\title{
Otimização do aproveitamento hídrico superficial no alto curso do rio Uberaba, Triângulo Mineiro
}

\author{
Optimization of surface water utilization in upper reach of the \\ Uberaba River, Triângulo Mineiro region
}

\author{
Emiliano Silva Costa ${ }^{1}$ \\ Marcio Ricardo Salla ${ }^{2}$ \\ Carlos Eugênio Pereira ${ }^{3}$ \\ José Eduardo Alamy Filho \\ Guilherme de Lima ${ }^{5}$
}

\begin{abstract}
Resumo
Os recursos hídricos têm importância acentuada no desenvolvimento econômico do Brasil e do mundo devido à multiplicidade em seus usos, como por exemplo, o abastecimento público, irrigação de culturas, geração de energia hidroelétrica, dessedentação de animais, entre outros. A fim de minimizar a pressão hídrica, instrumentos de gestão vêm sendo desenvolvidos para apoiar o planejamento e a gestão a nível de bacia hidrográfica. Sendo assim, o presente artigo teve como objetivo geral trazer alternativas de otimização do aproveitamento hídrico superficial no alto curso do rio Uberaba, Triângulo Mineiro. Verificou-se que a substituição da base de cálculo da vazão $\mathrm{Q}_{7,10}$ anual pela mensal no período chuvoso (dezembro até maio) e a manutenção da base de cálculo da vazão $Q_{7,10}$ anual no período de estiagem (junho até novembro) otimizou o aproveitamento hídrico superficial. Dentre os critérios para concessão de outorga, o critério de $50 \%$ da $\mathrm{Q}_{7,10}$ sazonal trouxe o maior aumento de vazão outorgável. Também, quanto à vazão remanescente no curso de água, a morfologia do trecho de rio Uberaba estudado garante a reoxigenação natural e a manutenção de área bentônica suficiente para a reprodução e desenvolvimento da vida aquática.
\end{abstract}

Palavras-chave: Otimização do aproveitamento hídrico; Vazão de referência; Área de Proteção Ambiental; Critério de outorga; Rio Uberaba.

\begin{abstract}
Water resources have major importance in Brazilian and global economic development because of water's multiple uses, such as drinking, irrigation, hydroelectric generation and livestock consumption, among others. Aiming to minimize water use pressure, computational tools are under development to support the planning and maintenance of water resources at the watershed level. This article has the general objective to discuss alternatives for optimization of surface water use in the upper reach of the
\end{abstract}

1,2,3,4,5Universidade Federal de Uberlândia, Uberlândia, Minas Gerais, Brasil.

${ }^{2}$ E-mail de contato: marcio.salla@ufu.br

Artigo recebido em: 19/01/2018. Aceito para publicação em: 24/04/2019. 
Uberaba River, located in the Triangulo Mineiro region of Minas Gerais, Brazil. We find that the replacement of the flow calculation on the yearly $\mathrm{Q}_{7,10}$ base by corresponding monthly base in the rainy season (December until May) and the maintenance of the yearly $\mathrm{Q}_{7,10}$ base in the dry season (June until November) can optimize the surface water use. Among the criteria for granting water use permission, the criterion of $50 \%$ of the seasonal $\mathrm{Q}_{7,10}$ brings the biggest increase of granted flow. Moreover, regarding the remaining flow in the watercourse, the morphology of the stretch of the Uberaba River studied guarantees the natural reoxygenation and maintenance of benthic area sufficient for the reproduction and development of aquatic life.

Keywords: Optimization water use; Reference flow; Environmental Protection Area; Procedure for permission to use; Uberaba river.

\section{Introdução}

O conflito pelo uso da água é consequência de ações humanas na expansão do desenvolvimento econômico, onde as demandas industriais, agrícolas e urbanas tornam-se cada vez maiores. As regiões do país que apresentam uma combinação de baixa disponibilidade e grande demanda hídrica passam por situações de escassez e estresse hídrico.

A outorga de direito do uso da água é um instrumento de gestão de recursos hídricos que tem o objetivo de assegurar o controle quantitativo e qualitativo da água superficial e subterrânea e o efetivo exercício dos direitos de acesso a este recurso natural. Para concessão de outorgas no Estado de Minas Gerais, segundo a Resolução Conjunta SEMAD-IGAM n ${ }^{\circ}$ 1.548/12 (SEMAD, 2012), adota-se como vazão de referência para outorga a fio de água, a vazão mínima com 7 dias de duração e 10 anos de recorrência $\left(\mathrm{Q}_{7,10}\right)$, aplicando-se o percentual de 50\% dessa vazão para a maior parte do estado. Segundo Castro et al. (2004), o critério adotado por Minas Gerais é o mais restritivo entre aqueles utilizados nos diversos Estado brasileiros, podendo dificultar, em alguns momentos, o deferimento de processos em situações que ainda há grande disponibilidade hídrica na bacia hidrográfica.

No intuito de minimizar a pressão sobre os recursos hídricos e os conflitos entre seus usuários, diversos estudos são realizados por órgãos 
gestores e instituições de ensino para otimizar o aproveitamento desses recursos (AMORIM JÚNIOR, 2014; ANA, 2009; 2014; BOF, 2010; FERREIRA, 2014; MAS, 2013; MOREIRA et al. 2014; OLIVEIRA et al. 2013; PAREDES-ARQUIOLA et al. 2010a, 2010b; SALLA et al. 2014a, 2014b; SILVA, 2012). Tais estudos são comumente realizados por meio de ferramentas computacionais, que auxiliam como um sistema de suporte à decisão em escala de bacia hidrográfica.

$\mathrm{Na}$ bacia hidrográfica do rio Uberaba, localizada na região do Triângulo Mineiro/MG, destaca-se um conflito de grande magnitude no período de estiagem, onde o rio não apresenta vazão suficiente para abastecimento público da cidade de Uberaba. Diante dessa problemática, desde o ano de 2002, uma das saídas emergenciais foi a transposição de parte da água do rio Claro, pertencente à bacia hidrográfica do rio Araguari, direto para um dos afluentes do alto curso do rio Uberaba (UBERABA, 2008).

Diante do exposto, o presente trabalho fundamenta-se na hipótese de que a variabilidade hídrica temporal e espacial e o uso de critérios menos restritivos aumentam a vazão outorgável na Área de Proteção Ambiental APA da bacia hidrográfica do rio Uberaba. O objetivo geral deste artigo foi otimizar o aproveitamento hídrico superficial na APA, a partir da análise de novos critérios de outorga e de sua sazonalidade em comparação com o critério atualmente vigente em Minas Gerais.

\section{Materiais e métodos}

\section{Área de estudo}

A APA da bacia hidrográfica do rio Uberaba abrange desde a cabeceira do rio até o ponto de captação superficial de água para abastecimento de Uberaba (Figura 1). Destaca-se por sua importância no 
abastecimento público da cidade de Uberaba, cuja população estimada é de 322.126 habitantes (IBGE, 2015), com retirada outorgada de $0,9 \mathrm{~m}^{3} / \mathrm{s}$, conforme Portaria IGAM n $\mathrm{n}^{0} 01656 / 2010$ (IGAM, 2010b). Nos meses de estiagem, entre agosto a outubro, existe a transposição outorgada de água de $0,56 \mathrm{~m}^{3} / \mathrm{s}$ do rio Claro (pertencente à bacia hidrográfica do rio Araguari) até o ribeirão da Saudade (Figura 1), que é o principal afluente da bacia hidrográfica do rio Uberaba.

A área total da APA é de $528,1 \mathrm{~km}^{2}$ e corresponde a $22 \%$ da área da bacia e $12 \%$ da área municipal. A APA foi dividida em 13 sub-bacias hidrográficas (com áreas maiores que $4 \mathrm{~km}^{2}$ ) (Figura 1). A sub-bacia identificada como "Difusa" engloba as sub-bacias com áreas percentuais inferiores a 1\% (que são afluentes do rio Uberaba) e as áreas difusas ao longo do curso de água (UBERABA, 2004).

Segundo a classificação climática de Köppen, o município de Uberaba é tropical quente úmido, com chuvas no verão (entre outubro e março) e seca no inverno (entre maio a setembro), com média anual de precipitação de $1.474 \mathrm{~mm}$ (FERNANDES et al., 2011). A temperatura média anual das máximas varia entre 27 e $30^{\circ} \mathrm{C}$ e as mínimas entre 15 e $18^{\circ} \mathrm{C}(\mathrm{CRUZ}, 2003)$.

Ainda de acordo com a Figura 1, com relação ao uso e ocupação do solo, a classe nomeada como vegetação nativa representou a vegetação destinada às áreas de preservação permanente (margens dos afluentes e do próprio rio Uberaba), ocupando $36,50 \%$ da área total da APA. A classe nomeada como vegetação cultivada representa as áreas destinadas ao plantio de culturas e/ou pastos, ocupando 4,97\% da área total. O solo exposto compreende o solo sem cobertura de vegetação que, na maior parte da área, encontra-se em processo de preparação para o plantio de culturas e/ou pastos, ocupando $57,47 \%$ da área total. A água é representada pelo principal curso de água, o rio Uberaba, e represamentos, ocupando apenas 0,34\% da área total. A área urbana representa as áreas impermeabilizadas (construções e rodovias), com apenas $0,72 \%$ da área total. De uma forma 
geral, considera-se a APA uma área homogênea do ponto de vista do uso e ocupação do solo, visto que as classes com maior percentual de ocupação são as classes correspondentes à vegetação nativa e solo exposto.

Figura 1 - Localização da área de estudo 


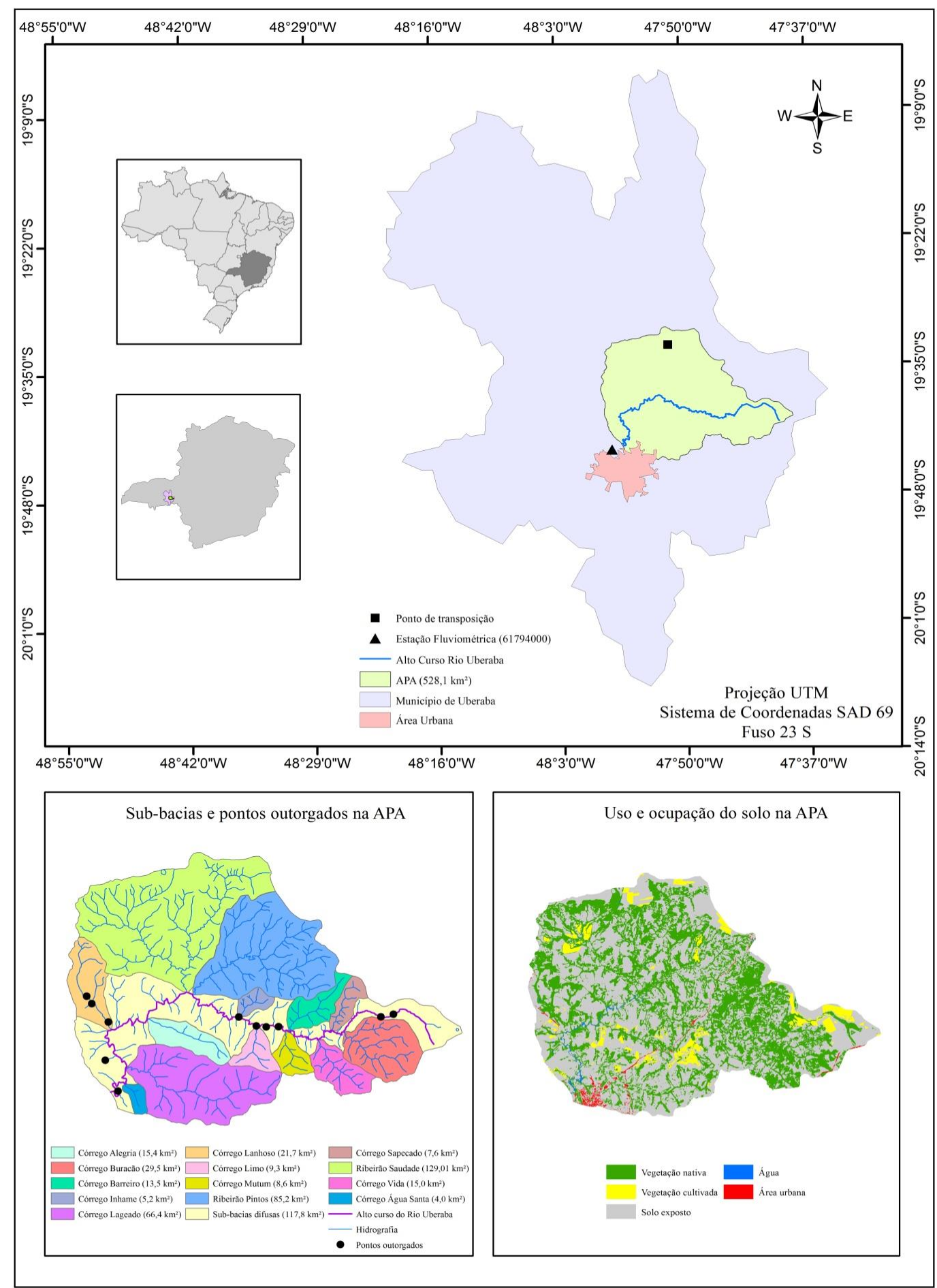

Org.: do Autor, 2016.

$\mathrm{Na}$ identificação do uso e ocupação do solo na APA recorreu-se ao geoprocessamento de imagem por meio de sensoriamento remoto (sensor Operacional Land Imager do satélite Landsat-8, resolução de $30 \mathrm{~m}$ ) e técnica 
de classificação supervisionada de imagem através da ferramenta computacional MultSpec W32.

De acordo com as informações fornecidas pela SUPRAM (2014), as outorgas superficiais concedidas na APA são destinadas ao abastecimento público, irrigação, dessedentação de animais e barramento com consumo. A maior demanda consuntiva outorgada refere-se ao abastecimento público da cidade de Uberaba, cujo valor fixo mensal é de $2,333 \mathrm{hm}^{3} / \mathrm{mês}$. As outras demandas atuais variam de 0,0052 a 0,0700 hm³/mês. A Figura 1 apresenta a espacialização dos pontos de outorga concedidas pelo IGAM no alto curso do rio Uberaba até maio de 2014.

\section{Metodologia hidrológica}

Faz parte deste estudo a estimativa e regionalização da vazão $Q_{7,10}$ para a otimização do aproveitamento hídrico superficial na APA, a partir da substituição das vazões de referência mínimas anuais pelas mínimas mensais e a partir das mudanças no critério de outorga pelo direito de uso da água.

A estimativa da $Q_{7,10}$ anual foi realizada por meio do programa computacional SisCAH 1.0 - Sistema Computacional para Análises Hidrológicas (SOUSA, 2009), e utilizou-se os dados da estação fluviométrica 61794000 naturalizada, com base na série histórica de 29 anos (compreendida entre 1977 a 2006), considerando-se para o cálculo o início do ano hidrológico em janeiro e descartando-se os anos com $5 \%$ ou mais de falhas na série histórica. Para a naturalização da vazão junto à estação fluviométrica (valor base para o cálculo da vazão de referência), foram adicionadas as vazões outorgadas às vazões medidas na estação.

Para a estimativa de $\mathrm{Q}_{7,10}$ mensal seguiu-se os mesmos procedimentos da estimativa da $Q_{7,10}$ anual, porém desta vez foram obtidos os valores de $Q_{7}$ para cada mês, de cada ano do período base, e o conjunto de todos os valores 
de $Q_{7}$ em cada mês constituiu-se uma nova série de eventos. Para as séries de eventos de $Q_{7}$, tanto anual quanto mensal, aplicou-se a análise das distribuições de probabilidade. A melhor estimativa dos valores de $Q_{7,10}$ corresponde a distribuição de densidade de probabilidade que apresenta menor amplitude do intervalo de confiança dentre as estimativas obtidas por cada distribuição.

As vazões mínimas $Q_{7,10}$ nas diversas sub-bacias hidrográficas foram estimadas por meio de regionalização via vazão específica, de acordo com a Equação 1. A área de estudo considerada pequena e homogênea do ponto de vista de uso e ocupação do solo (Figura 1) e o número reduzido de postos fluviométricos na bacia hidrográfica são aspectos favoráveis à utilização desta metodologia (CHAVES et al., 2002; SILVA et al., 2009).

$$
Q_{7,10 i}=\left(A_{i} / A_{\text {total }}\right) . Q_{7,10 \text { alto curso do rio Uberaba }}
$$

Na qual: $Q_{7,10 i}$ é a vazão estimada na sub-bacia $i\left(\mathrm{~m}^{3} / \mathrm{s}\right) ; Q_{7,10}$ alto curso do rio Uberaba é a vazão $\mathrm{Q}_{7,10}$ obtida no alto curso do rio Uberaba $\left(\mathrm{m}^{3} / \mathrm{s}\right) ; A_{\text {total }}$ é a área total da bacia de contribuição da estação fluviométrica $\left(\mathrm{km}^{2}\right) ; A_{i}$ é a área de contribuição da sub-bacia $i\left(\mathrm{~km}^{2}\right)$ (Figura 1).

\section{Otimização hídrica na APA}

Esta avaliação foi realizada por meio de comparação da vazão outorgável atual (considerando os critérios atuais para outorga) com a vazão outorgável para situações distintas, seja pelo período mensal ou anual e/ou pela mudança de critério de outorga. A metodologia de avaliação de vazão outorgável é baseada em Bof (2010) e Oliveira et al. (2013).

A criação da topologia do sistema hídrico e o consequente balanço hídrico para cada configuração (situação atual e as diversas situações distintas) foram realizados na ferramenta computacional AQUATOOL 
(SOLERA et al., 2007). De acordo com a topologia ilustrada na Figura 2, as análises comparativas foram realizadas em: foz de cada córrego afluente ao rio Uberaba, nó de jusante de cada trecho na APA, totalizando 14 trechos e nomeados de T1 a T14, além de um trecho a montante do trecho T1, identificado como "bacia difusa 1", que corresponde ao trecho entre a nascente do rio Uberaba e a confluência deste com o primeiro afluente (córrego Buracão).

Figura 2 - Topologia do sistema hídrico

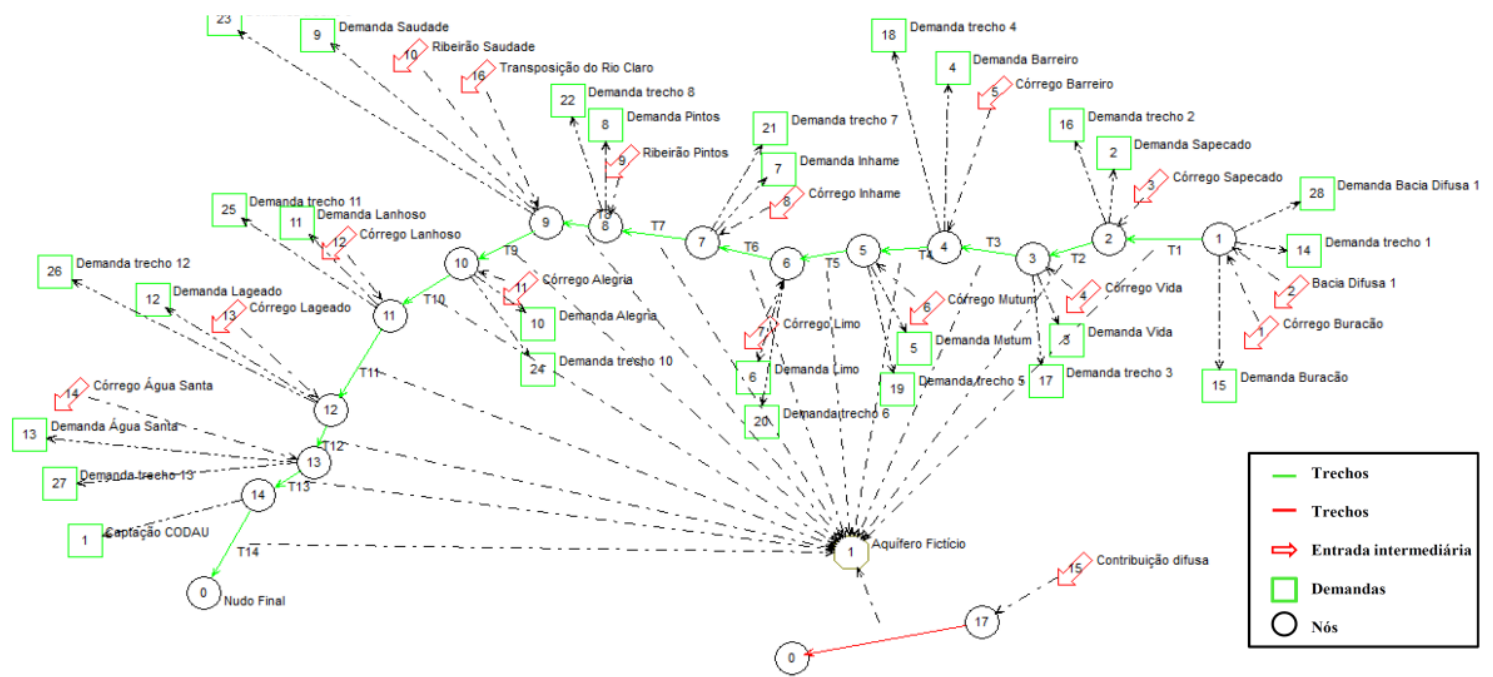

Org.: do Autor, 2016.

$\mathrm{Na}$ ferramenta AQUATOOL, os trajetos no curso de água são representados por trechos (a seta verde representa um canal impermeável, sem conexão com o aquífero, enquanto a seta vermelha representa um canal com infiltração total da água ao aquífero fictício). As entradas intermediárias representam todos os tributários e entradas difusas, enquanto as demandas representam as retiradas outorgadas no trecho de rio e nas sub-bacias afluentes. Os elementos nós são posicionados em todas as confluências entre o rio Uberaba com os tributários e as demandas. O aquífero fictício teve a função de receber toda a contribuição difusa e distribuí-la (sem perdas) ao longo dos 14 trechos do rio Uberaba (Figura 2). 
- Substituição da vazão de referência mínima anual pela mínima mensal

A análise comparativa entre a situação atual e a otimizada de vazão outorgável foi realizada por meio da Equação 2. Nesta equação, a situação atual é representada pela vazão $Q_{\text {anual }}$ e a situação otimizada é representada

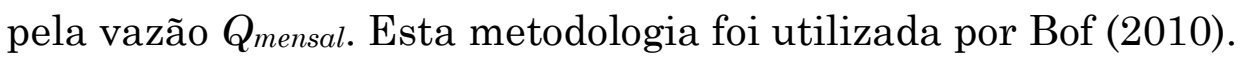

$$
D R \%=\left\{\left(Q_{\text {mensal }}-Q_{\text {anual }}\right) / Q_{\text {anual }}\right\} .100
$$

Na qual: $D R \%$ é a diferença relativa entre a situação otimizada mensal e a anual (\%); Qmensal é a $Q_{7,10}$ obtida em base mensal (m³/s); Qanual é a $Q_{7,10}$ obtida em base anual $\left(\mathrm{m}^{3} / \mathrm{s}\right)$.

\section{- Alteração no critério de outorga}

Foram avaliadas as alterações no critério de outorga para as vazões mínimas de referência anual e mensal, como seguem:

- Uso de $30 \%$ da $\mathrm{Q}_{7,10}$ anual: analisou-se este critério devido ao percentual $30 \%$ ainda ser utilizado para concessão de outorga em algumas bacias hidrográficas no Estado de Minas Gerais. Isso implica que deverá ser mantida uma vazão mínima de $70 \%$ da $\mathrm{Q}_{7,10}$ no curso de água;

- Uso de $50 \%$ da $Q_{7,10}$ anual e mensal: atual critério utilizado no estado de Minas Gerais, de acordo com a Resolução Conjunta SEMAD-IGAM 1.548/12 (SEMAD, 2012). Isso implica que deverá ser mantida uma vazão mínima de $50 \%$ da $\mathrm{Q}_{7,10}$ no curso de água;

- Uso de $70 \%$ da $Q_{7,10}$ anual: esse critério foi avaliado a fim de superestimar a vazão outorgável, e avaliar a vazão outorgável com um critério menos restritivo. Isso implica que deverá ser mantida uma vazão mínima de $30 \%$ da $\mathbf{Q}_{7,10}$ no curso de água. 
Para identificar, em cada trecho do rio, o percentual utilizado de outorgas a partir dos critérios listados, considerou-se a vazão mínima de referência e as outorgas já emitidas a montante do trecho estudado e no próprio trecho. Nesse sentido, o percentual já outorgado em cada trecho é expresso pela Equação 3.

$$
Q_{\text {outorgada }(\%)}=\left(\sum Q_{m t i} \cdot 100\right) /\left\{(x / 100) \cdot Q_{7,10}\right\}
$$

Na qual: Qoutorgada i (\%) é o percentual utilizado da parcela da $Q_{7,10}$ permissível para outorga no segmento i $\left(\mathrm{m}^{3} / \mathrm{s}\right) ; x$ é a porcentagem da $Q_{7,10}$ permissível para outorga (\%) - é um dos critérios definidos anteriormente; $\sum Q_{m t} i$ é o somatório das vazões já outorgadas a montante do segmento $i$, inclusive as vazões outorgadas no próprio segmento $i\left(\mathrm{~m}^{3} / \mathrm{s}\right)$.

Os resultados foram avaliados nas sub-bacias e nos trechos ("Bacia difusa 1" e T1 a T14) na APA, onde foram elaborados mapas em que os trechos foram coloridos de acordo com a proporção de utilização da parcela permissível para outorga (de acordo com cada critério estabelecido) da vazão Q7,10. Esta metodologia foi inicialmente utilizada por Oliveira et al. (2013).

\section{Resultados e discussões}

\section{Substituição da $Q_{7,10}$ anual pela mensal}

A vazão $\mathrm{Q}_{7,10}$ anual obtida na foz da APA (trecho T14), próximo ao reservatório de acumulação para abastecimento público de Uberaba, corresponde a $0,36 \mathrm{~m}^{3} / \mathrm{s}$. Ainda neste trecho, observa-se que a DR apresenta variação acentuada ao longo do ano, atingindo valores maiores que 100\% entre os meses de dezembro a agosto. Em contrapartida, nota-se que nos meses de setembro, outubro e novembro, que são os meses mais secos do ano, os valores de DR resultaram menores que 100\%. A vazão $Q_{7,10}$ 
calculada em base mensal teve maior DR com a vazão calculada em base anual de $2.389 \%$ no mês de fevereiro. Porém, no mês de outubro a vazão calculada em base mensal apresentou valor inferior ao calculado em base anual, cujo DR apresentou redução de 52,7\% (Figura 3).

Figura 3 - DR entre as vazões Q7,10 anual e mensal

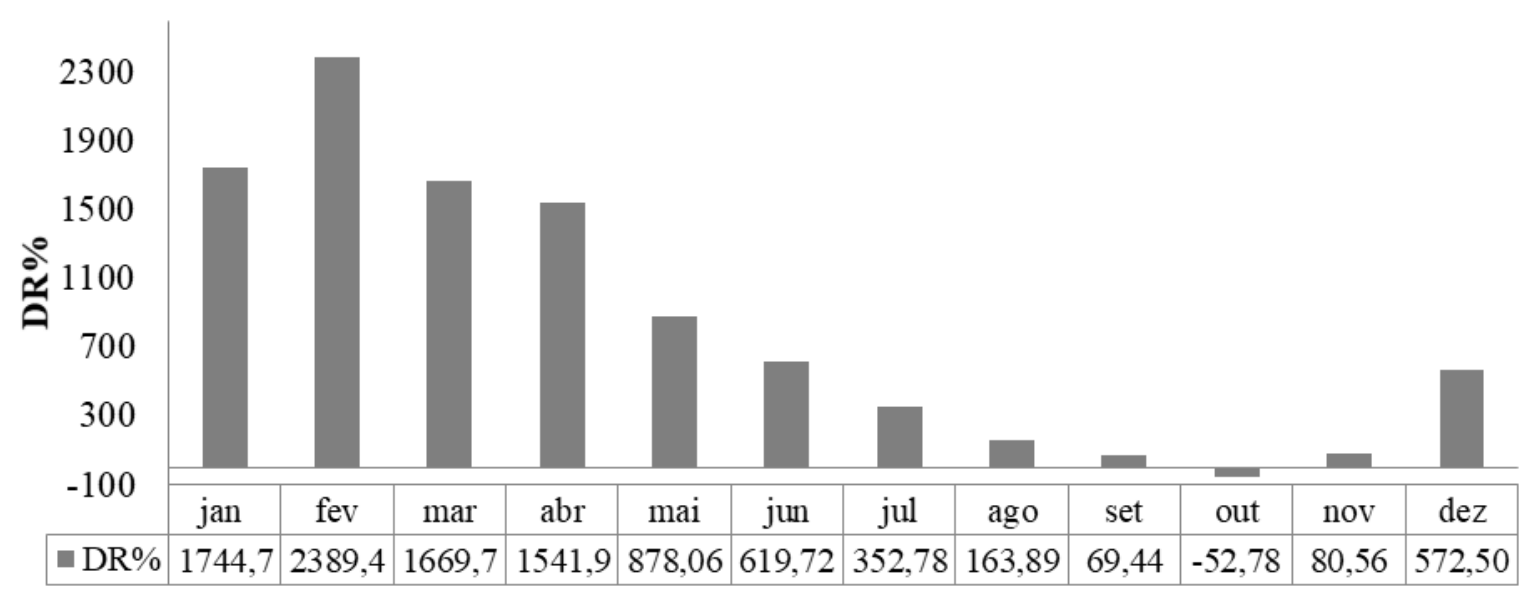

Org.: do Autor, 2016.

Contudo, verifica-se que a sazonalidade no cálculo da vazão outorgável, ou seja, a substituição da base de cálculo da vazão $Q_{7,10}$ anual pela mensal no período chuvoso (dezembro até maio) e a manutenção da base de cálculo da vazão $\mathrm{Q}_{7,10}$ anual no período de estiagem (junho até novembro), otimizaria o aproveitamento hídrico superficial na APA, cujas principais justificativas são:

- Conforme já mencionado anteriormente, o Centro Operacional de Desenvolvimento e Saneamento de Uberaba - CODAU possui uma outorga de $0,9 \mathrm{~m}^{3} / \mathrm{s}$ para o abastecimento público da cidade de Uberaba, conforme Portaria IGAM nº 01656/2010 (IGAM, 2010b). Em função da base de cálculo da vazão $Q_{7,10}$ anual, existe a transposição outorgada de água de $0,56 \mathrm{~m}^{3} / \mathrm{s}$ do rio Claro até o ribeirão da Saudade. Neste contexto, nos meses chuvosos, o potencial de acumulação do excedente em reservatório de sobras supriria o 
déficit no abastecimento de água da cidade de Uberaba entre os meses de aogosto e outubro, eliminando a necessidade de transposição;

- Em função da vazão outorgada ser constante ao longo do ano, a manutenção da base de cálculo da vazão $Q_{7,10}$ anual no período de estiagem seria suficiente para atender as demandas outorgadas.

É importante salientar que esta sazonalidade no cálculo da vazão outorgável manteria as condições ambientais favoráveis ao ecossistema aquático. A morfologia do trecho de rio Uberaba estudado, especificamente em função da existência de pequenas cascatas e afloramento de pedras basálticas em algumas regiões, favorece a reoxigenação natural do curso de água (SALLA et al., 2015). Também, em outras regiões do rio Uberaba, a baixa declividade longitudinal do canal associada à uma seção transversal bem definida (sem obstruções) favorece a reprodução e desenvolvimento da vida aquática, isso por que a velocidade reduzida do escoamento e o aumento do perímetro molhado favorece o habitat da ictiofauna (ANA, 2004; DE PAULO, 2007).

\section{Mudança no critério de outorga}

- $30 \%$ da $Q_{7,10}$ anual

A concessão de outorga baseada no critério de $30 \%$ da $Q_{7,10}$ anual foi utilizada em todo o estado de Minas Gerais até a promulgação da Resolução Conjunta SEMAD-IGAM no 1.548/12 (SEMAD, 2012), que estabeleceu o critério de 50\% da mesma vazão de referência. Porém, em algumas bacias hidrográficas estaduais ainda é aplicado o antigo percentual. $\mathrm{Na}$ bacia hidrográfica do rio Uberaba utiliza-se o percentual de 50\% da $\mathrm{Q}_{7,10}$ anual, porém avaliou-se o percentual hídrico utilizado para 30\% (Figura 4a). 
Figura 4 - Análise do percentual hídrico utilizado, considerando: a) $30 \%$ da vazão $\mathrm{Q}_{7,10}$ anual; b) 50\% da vazão $\mathrm{Q}_{7,10}$ anual

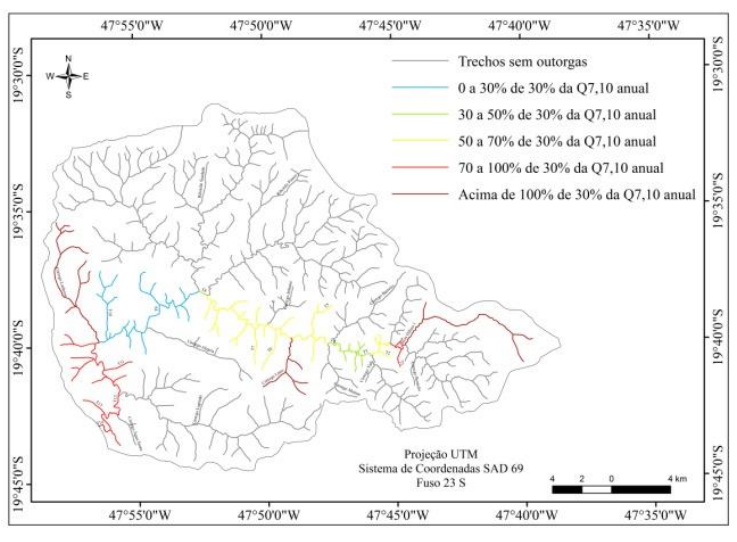

(a)

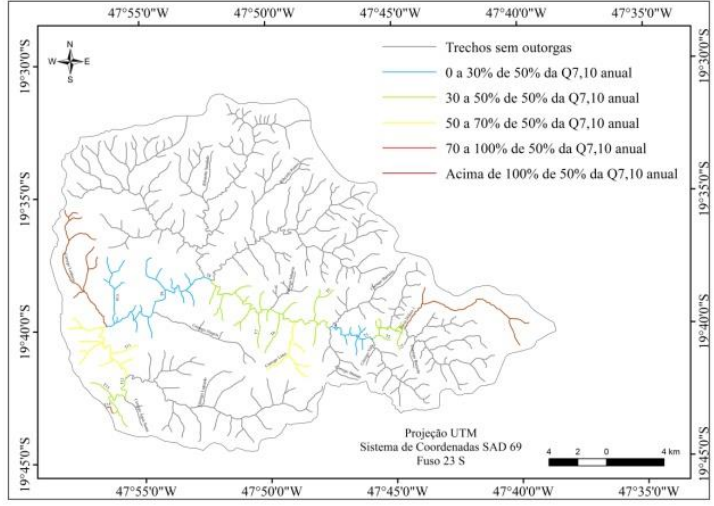

(b)

Org.: do Autor, 2016.

Ao aplicar o critério de $30 \%$ da $\mathrm{Q}_{7,10}$ anual (Figura $4 \mathrm{a}$ ), os afluentes com outorgas apresentam vazão outorgada acima de $100 \%$ da vazão permitida. Quanto aos trechos do rio Uberaba, o primeiro trecho nomeado como "Bacia difusa 1" e T14 apresentam valor outorgado acima de 100\% da vazão permitida. Os trechos T1, T11, T12 e T13 apresentam vazões outorgadas de 70 a 100\% do permitido. Os trechos T2, T5, T6 e T7 apresentam vazões outorgadas de 50 a $70 \%$ do valor permitido, e os trechos restantes apresentam boa disponibilidade hídrica, indicando que os valores outorgados alcançaram 50\% ou menos. Os resultados da análise deste critério indicam que grande parte da hidrografia do alto curso do rio Uberaba apresenta conflito pelo uso da água. Dessa forma, confirma-se a necessidade de adotar critérios menos restritivos, como foi o caso do percentual estabelecido pela nova resolução. 
- $50 \%$ da $Q_{7,10}$ anual e mensal

Esta análise permite a comparação entre o critério atual de outorga em Minas Gerais (base anual) com outro critério menos restritivo (base mensal).

A Figura 4b traz a situação real de concessão de outorgas na APA a partir de 50\% da vazão $\mathrm{Q}_{7,10}$ anual. Observa-se que alguns trechos da hidrografia apresentam situação crítica na disponibilidade hídrica outorgável, visto que o trecho inicial do rio "Bacia difusa 1", a sub-bacia do córrego Lanhoso e o trecho após a captação de água do CODAU (T14) apresentam vazão outorgada maior que $100 \%$ do valor permitido, comprometendo a disponibilidade hídrica nos trechos a jusante.

A Figura 5 traz o percentual hídrico utilizado baseado em uma situação otimizada, considerando o critério de $50 \%$ da vazão $\mathrm{Q}_{7,10}$ calculada em base mensal. Observa-se que, mesmo com este critério bem menos restritivo, a hidrografia apresentou conflitos em diversos meses (junho até dezembro), com as situações mais críticas na sub-bacia do córrego Lanhoso e no trecho T14. O trecho "Bacia difusa 1" apresentou percentual acima de $100 \%$ de utilização da parcela permitida para outorga nos meses de setembro e outubro (Figura 5). 
Figura 5 - Análise do percentual hídrico utilizado, baseado em 50\% da vazão Q7,10 mensal, de janeiro (a) até dezembro (l)

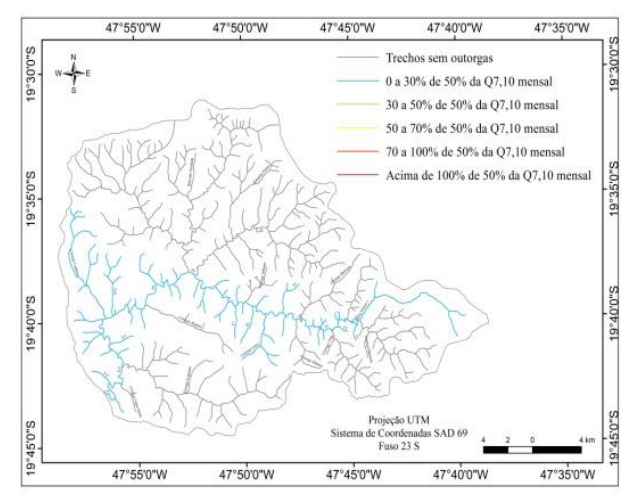

(a)

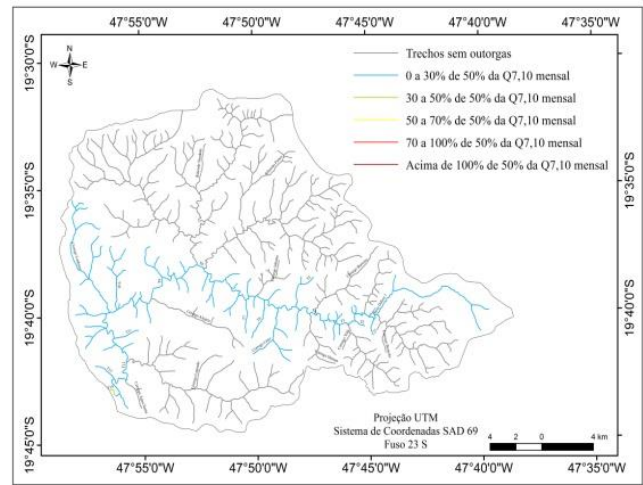

(c)

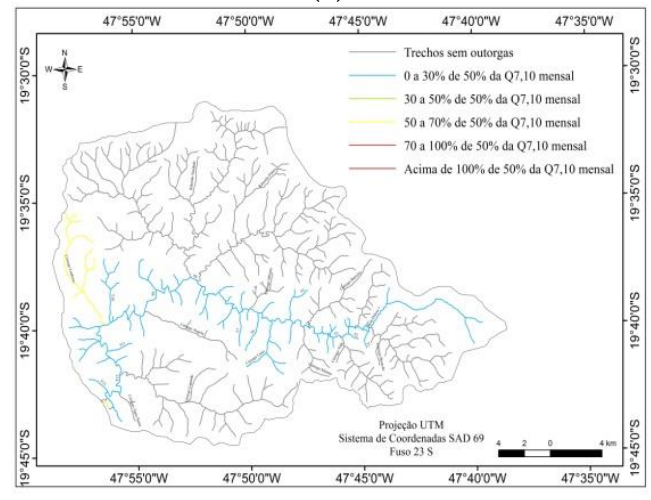

(e)

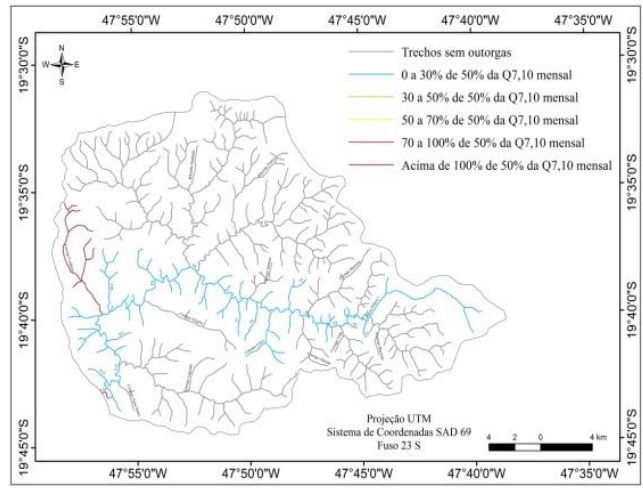

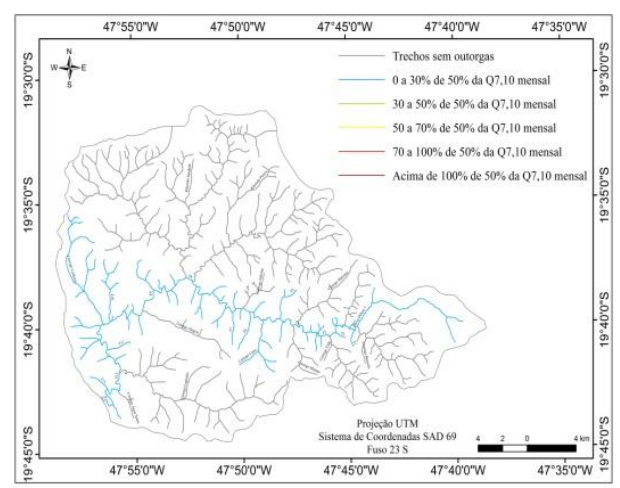

(b)

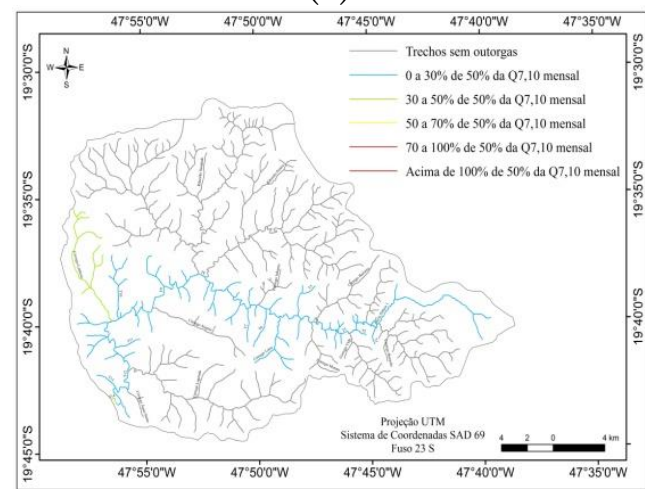

(d)

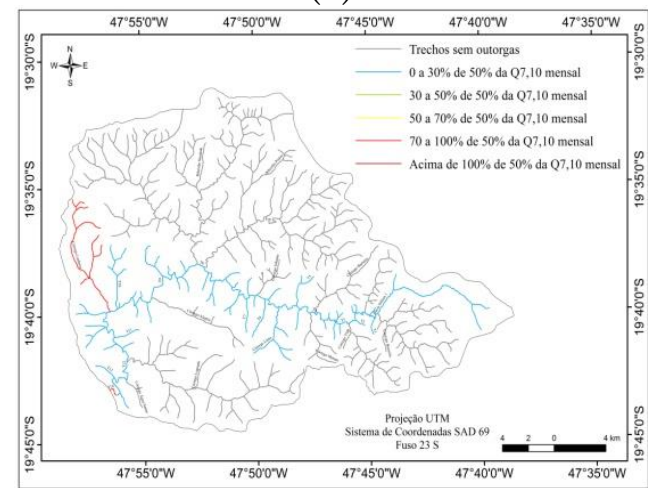

(f)

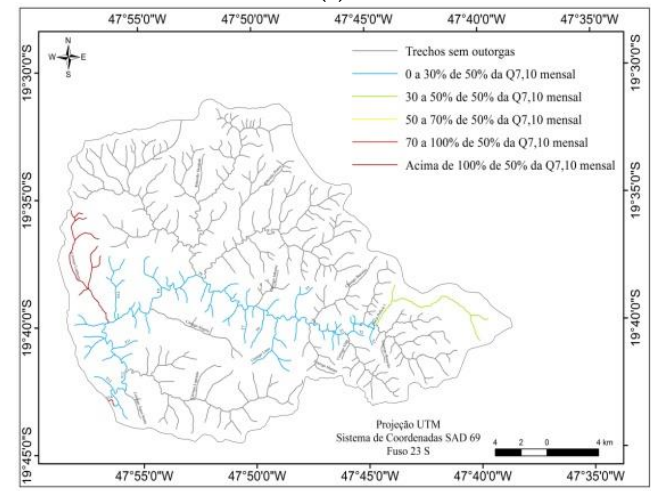


$(\mathrm{g})$

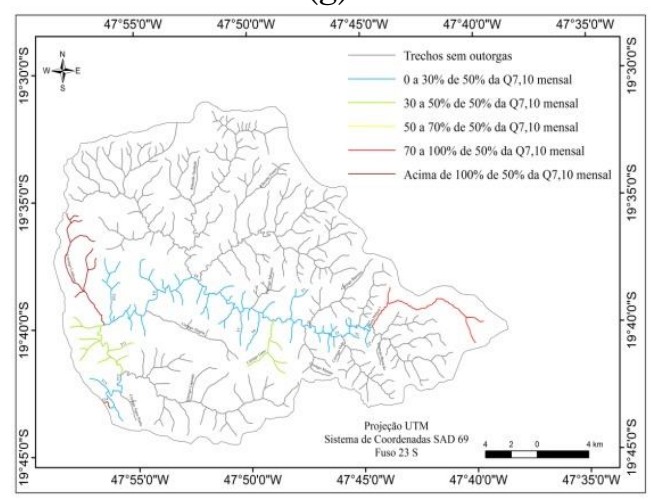

(i)

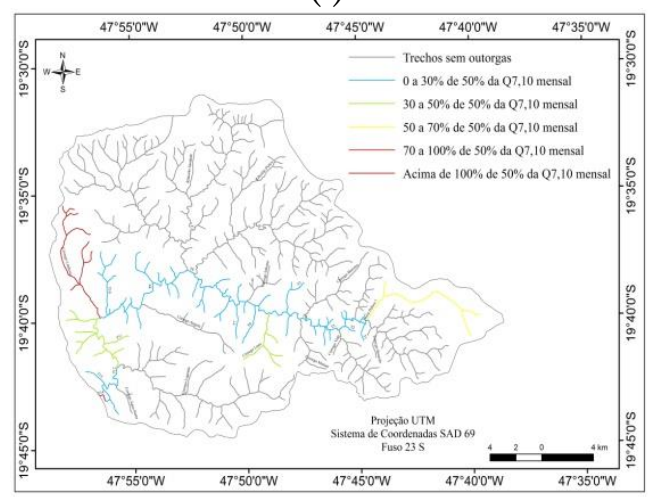

(k) (h)

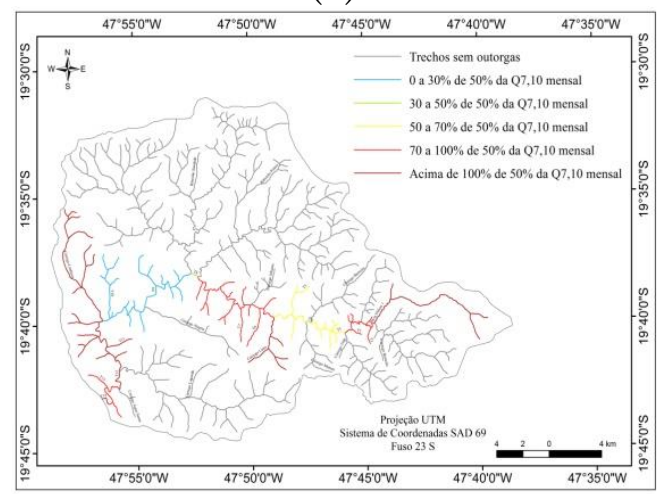

(j)

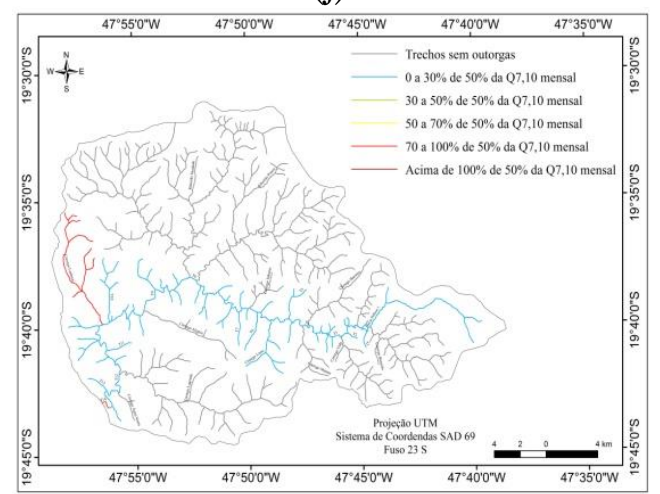

(l)

Org.: do Autor, 2016.

Para os meses mais chuvosos (janeiro, fevereiro, março e abril), o critério de outorga menos restritivo aumentou significativamente a disponibilidade hídrica em comparação com a disponibilidade calculada a partir de base anual. Observa-se que nos meses de janeiro e fevereiro todas as sub-bacias e todos os trechos apresentaram percentual de utilização da água de 0 a $30 \%$ da parcela permitida para outorga, enquanto que nos meses de março e abril esse cenário prevaleceu, com exceção na sub-bacia do córrego Lanhoso e trecho T14, com utilização de 30 a 50\%.

- 70\% da $Q_{7,10}$ anual

O critério de vazão outorgável baseado no uso de $70 \%$ da $Q_{7,10}$ anual foi proposto com o intuito de superestimar o volume outorgado para suprir 
as demandas de abastecimento público e irrigação. Observa-se que alguns trechos do alto curso do rio Uberaba ainda se encontram fora de conformidade com o critério proposto (Figura 6). A maior parte da hidrografia apresentou disponibilidade hídrica outorgável positiva, indicando que ainda há volume disponível a ser outorgado.

Figura 6 - Análise do percentual hídrico utilizado, baseado em 70\% da vazão Q7,10 anual

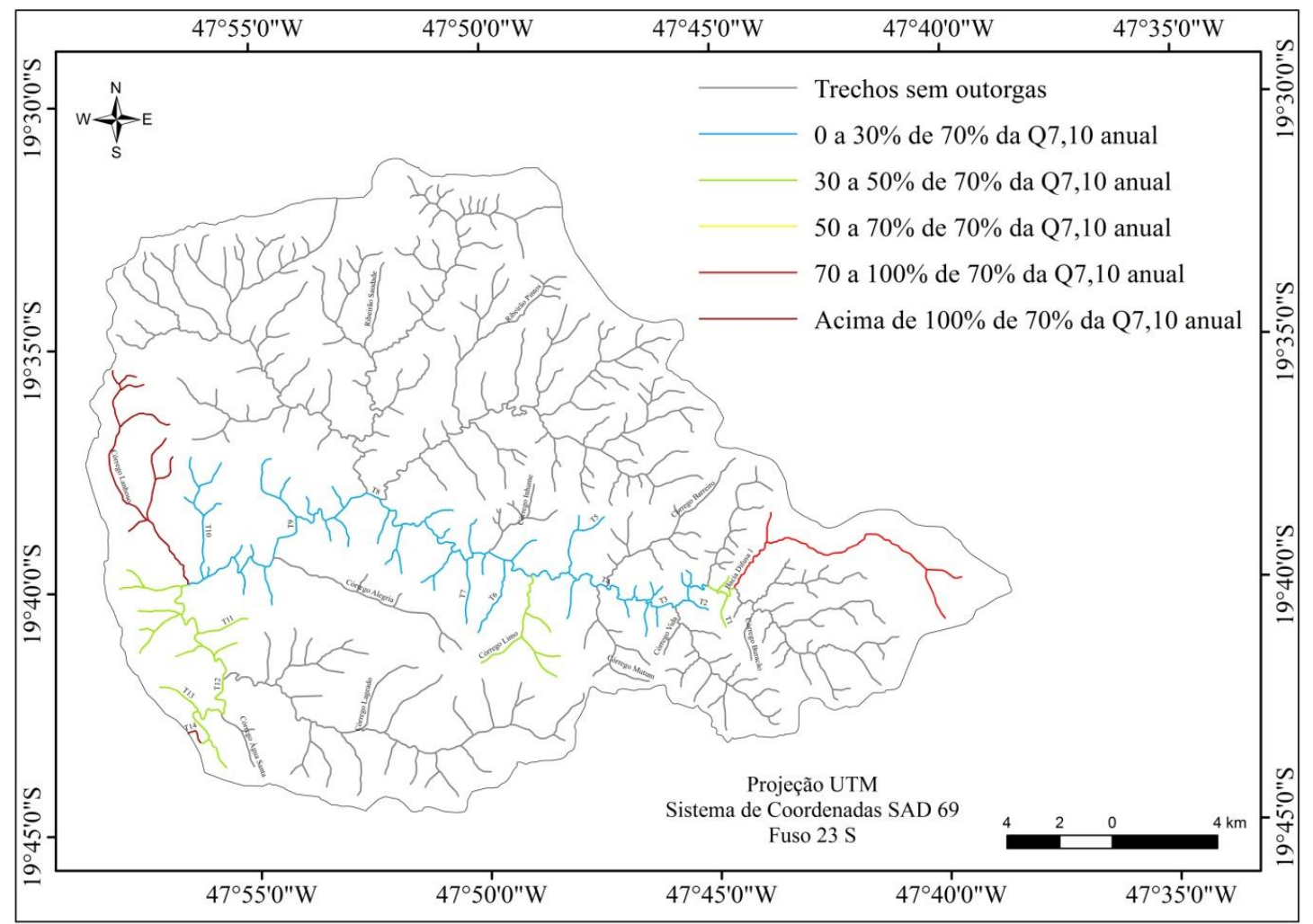

Org.: do Autor, 2016.

De uma forma geral, a situação mais crítica encontra-se no trecho inicial do rio, identificado com Bacia difusa 1, e na sub-bacia do córrego Lanhoso, com o percentual hídrico utilizado de 70 - 100\% e maior que $100 \%$ da vazão de referência, respectivamente.

Para todas as mudanças no critério de outorga discutidas anteriormente, a otimização do aproveitamento hídrico superficial esteve em consonância com a manutenção do ecossistema aquático. Como já discutido, 
a morfologia do trecho de rio Uberaba estudado favorece a manutenção do habitat da ictiofauna.

A literatura da área traz diversos estudos relacionados à otimização do aproveitamento hídrico superficial a partir da mudança de critério de outorga. De acordo com Bof (2010), em seu estudo na bacia hidrográfica do rio Paraopeba, o critério de outorga da vazão $Q_{7,10}$ mensal "potencializa um melhor plano de utilização da água, à medida que permite um maior uso da mesma nos períodos em que há disponibilidade hídrica e impõe uma restrição mais realista nos períodos críticos".

Já Oliveira (2011) e Oliveira et al. (2013) concluíram que a sazonalidade da vazão outorgável foi satisfatória na otimização do aproveitamento da disponibilidade de águas superficiais na bacia hidrográfica do Ribeirão Entre Ribeiros. Mesma afirmação quanto à sazonalidade da vazão foi feita por Euclydes et al. (2006), no estudo de critério de outorga sazonal para a agricultura irrigada na bacia hidrográfica do rio Grande, Minas Gerais, e por Maia (2003) na bacia hidrográfica do Alto Sapucaí, Minas Gerais.

\section{Considerações finais}

Existem diversos critérios para emissão de outorga pelo uso da água superficial, além dos critérios aqui apresentados, adaptáveis às diferentes regiões do território nacional em função das demandas, das condições climáticas e das características morfológicas do curso de água.

Este estudo apontou que a sazonalidade no cálculo da vazão outorgável é positiva na APA, principalmente pela possibilidade de reservação no período chuvoso para atendimento principalmente à demanda de abastecimento público de Uberaba/MG. 


\section{Agradecimentos}

Os autores agradecem a Coordenação de Aperfeiçoamento de Pessoal de Nível Superior - CAPES pela bolsa de mestrado fornecida ao primeiro autor e a Fundação de Amparo à Pesquisa do Estado de Minas Gerais FAPEMIG pelo apoio financeiro concedido via Processo APQ-CRA-01024/14 - Demanda Universal.

\section{Referências}

AMORIM JÚNIOR, J. C. Disponibilidade hídrica para outorga de captação: critérios anual e mensal para definição de vazões mínimas de referência. 2014. Dissertação (Mestrado) Universidade Federal do Espírito Santo, Vitória, ES, 2014.

ANA - Agência Nacional de Águas (2004). Plano Decenal de Recursos Hídricos da Bacia Hidrográfica do Rio São Francisco - PBHSF (2004-2013). Estudo Técnico de Apoio ao PBHSF - $\mathrm{N}^{\mathrm{o}}$ 16: Alocação de Água. 2004. Disponível em: < http://www.saofrancisco.cbh.gov.br/docs/planos/PlanoDecenaldeRecursosHidricos.pdf $>$. Acesso em: 15 de janeiro de 2015.

ANA - Agência Nacional de Águas. Plano estratégico de recursos hídricos da bacia hidrográfica dos rios Tocantins e Araguaia. 2009. Disponível em: < https://www.senado.gov.br/comissoes/CDR/AP/AP20090528_ANA-

Jos\%C 3\%A9LuizZobiRioTocantins-Araguaia.pdf >. Acesso em: 15 de janeiro de 2015.

ANA - Agência Nacional de Águas. Subsídios para a discussão da compatibilização da geração de energia hidrelétrica com expansão da agricultura irrigada na bacia do rio São Marcos. 2014. Disponível em: <file://C:/Users/Marcio/Downloads/UsosMultiplosdaAguanabaciadoRioSaoMarcos\%20(2).pd $\mathrm{f}>$. Acesso em: 16 de janeiro de 2015.

BOF, L. H. N. Análise de critérios de outorga de direito de uso de recursos hídricos. 2010. Dissertação (Mestrado) - Universidade Federal de Viçosa, Viçosa, MG. 2010.

CASTRO, L. M. A.; DINIZ, M. G. M.; SILVA, A. G. Aplicação do instrumento da outorga no gerenciamento dos recursos hídricos em Minas Gerais: A bacia do Ribeirão Entre Ribeiros. In: SIMPÓSIO DE RECURSOS HÍDRICOS DO NORDESTE, 2004, São Luis. Anais... São Luis: ABRH, 2004.

CHAVES, H. M. L.; ROSA, J. W. C.; VADAS, R. G.; OLIVEIRA, R. V. T. Regionalização de vazões mínimas em bacia através de interpolação e em Sistemas de Informação Geográfica. Revista Brasileira de Recursos Hídricos, Porto Alegre, v. 7, n. 3, p. 43-51. 2002. https://doi.org/10.21168/rbrh.v7n3.p43-51

CRUZ, L. B. S. Diagnóstico ambiental da bacia hidrográfica do rio Uberaba-MG. 2003. Tese (Doutorado) - Universidade Estadual de Campinas, Campinas, SP. 2003.

DE PAULO, R.G.F. Ferramentas para a determinação de vazões ecológicas em trechos de vazão reduzida: destaque para a aplicação do método do perímetro molhado no caso de Capim Branco I. 2007. Dissertação (Mestrado) - Programa de Pós-graduação em Saneamento, Meio Ambiente e Recursos Hídricos. Universidade Federal de Minas Gerais, Belo Horizonte, MG, 2007. 
EUCLYDES, H.P.; FERREIRA, P.A.; FILHO, R.F.F. Critério de outorga sazonal para a agricultura irrigada no estado de minas gerais. Estudo de caso. Revista ITEM - Irrigação \& Tecnologia Moderna, v. 71-72, n. 3-4, p. 42-50. 2006.

FERNANDES, A. L. T.; FRAGA JÚNIOR, E. F.; TAKAY, B. Y. Avaliação do método Penman-Piche para a estimativa da evapotranspiração de referência em Uberaba, MG. Revista Brasileira de Engenharia Agrícola e Ambiental, v. 15, n.3, p.270-276, 2011. https://doi.org/10.1590/S1415-43662011000300008

FERREIRA, A. M. Capacidade de autodepuração nos cursos médio e baixo do rio Uberaba, UPGRH-GD8. 2014. Dissertação (Mestrado) - Universidade Federal de Uberlândia, Uberlândia, MG, 2014.

IBGE - Instituto Brasileiro de Geografia e Estatística. Cidades. Disponível em: $<$ http://www.ibge.gov.br>. Acesso em: 28 nov. 2015.

IGAM. Instituto Mineiro de Gestão das Águas. Parecer Técnico sobre a Outorga de Portaria $\mathbf{n}^{\mathbf{0}}$ 01656, de 19 de junho de 2010. 2010a. Disponível em: < file:///C:/Users/Marcio/Downloads/ITEM 8.2 CODAU -

Centro_Operacional_de_Desenvolvimento_e_Saneamento_de_Uberaba.pdf $>$. Acesso em: 20 fev. 2014.

IGAM. Instituto Mineiro de Gestão das Águas. Portaria IGAM n. ${ }^{\mathbf{0}}$ 01656, 19 de junho de 2010. 2010b. Disponível em: <http://www.igam.mg.gov.br/component/docman/cat_view/14portarias-de-outorga >. Acesso em: 20 fev. 2014.

MAIA, J.L. Estabelecimento de Vazões de Outorga na Bacia Hidrográfica do Alto Sapucaí, com a utilização de sazonalidade. 2003. 116 p. Dissertação (Mestrado em Engenharia de Energia) - Universidade Federal de Itajubá, Itajubá, 2003.

MAS, A. G. C. Evaluación del recurso hídrico en la cuenca del río Turia (España) mediante la aplicación de modelos semiagregados de Precipitación-Escorrentía. 2013. Proyecto Final de Carrera. Ingeniería de Caminos, Canales y Puertos, Universidad Politécnica de Valencia, Valencia, 147 p., 2013.

MOREIRA, M. C.; SILVA, D. D. da.; LARA, M. dos. S.; PRUSKI, F. F. Índices de conflito pelo uso da água da bacia do Ribeirão entre Ribeiros. Revista Brasileira de Recursos Hídricos, Porto Alegre, v. 19, n. 1, p. 221-228 - jan/mar, 2014. https://doi.org/10.21168/rbrh.v19n1.p221-228

OLIVEIRA, J. R. S. Otimização do aproveitamento da disponibilidade de águas superficiais na bacia do Ribeirão Entre Ribeiros. 2011. 86 p. Dissertação (Mestrado em Engenharia Agrícola) - Universidade Federal de Viçosa, Viçosa, 2011.

OLIVEIRA, J. R. S.; PRUSKI, F. F.; NUNES, A. A. Otimização do aproveitamento da disponibilidade de Águas Superficiais na Bacia do Ribeirão entre Ribeiros. Revista Brasileira de Recursos Hídricos, v. 18, n. 4, 157-172, 2013. https://doi.org/10.21168/rbrh.v18n4.p157-172

PAREDES-ARQUIOLA, J.; ÁLVAREZ, J. A.; SOLERA, A. A decision support system for water quality issues in the Manzanares River (Madrid, Spain). Science of the Total $\begin{array}{lllllll}\text { Environment, } & \text { v. } & 408, & \text { n. } & 12, & \text { p. } & 2576-2589,\end{array}$ https://doi.org/10.1016/j.scitotenv.2010.02.037

PAREDES-ARQUIOLA, J.; ÁLVAREZ, J. A.; MONERRIS, M. M.; SOLERA, A. Water quantity and quality models applied to the Jucar River Basin, Spain. Water Resources Management, v. 24, n. 11, p. 2759-2779, 2010b. https://doi.org/10.1007/s11269-010-9578-z RIBEIRO, M. M. R.; LANNA, A. E. L. A outorga integrada das vazões de captação e diluição. Revista Brasileira de Recursos Hídricos, Porto Alegre, v. 8, n. 3, p. 151-168, 2003. https://doi.org/10.21168/rbrh.v8n3.p151-168

SALLA, M. R.; PAREDES-ARQUIOLA J.; SOLERA, A.; ÁLVAREZ, J. A.; PEREIRA, C. E.; ALAMY FILHO, J. E.; OLIVEIRA, A. L. de. Integrated modeling of water quantity and quality in the Araguari River basin, Brazil. Latin American Journal of Aquatic Research, Valparaíso, v. 42, n. 1, p. 224-244, 2014a. https://doi.org/10.3856/vol42-issue1$\underline{\text { fulltext-19 }}$ 
SALLA, M. R.; PAREDES-ARQUIOLA J.; SOLERA, A.; ÁlVAREZ, J. A.; PEREIRA, C. E.; ALAMY FILHO, J. E.; OLIVEIRA, A. L. de. Sistema de Suporte à Decisão em Recursos Hídricos na Bacia Hidrográfica do Rio Uberabinha, Minas Gerais. Revista Brasileira de Recursos Hídricos, Porto Alegre, v. 19, n. 1, p. 189-204. 2014b. https://doi.org/10.21168/rbrh.v19n1.p189-204

SALLA, M. R.; MAGALHÃES, A.A.B.; ALVES, L. A. ;SCHMIDT, M. A. R. ; LIMA, G. Sensibilidade de características morfológicas no comportamento de parâmetros de qualidade da água em rio de porte médio. Ciência \& Engenharia, v. 24, p. 29-37, 2015. https://doi.org/10.14393/19834071.2015.32256

SEMAD. Secretaria de Estado de Meio Ambiente e Desenvolvimento Sustentável. Resolução Conjunta SEMAD-IGAM n. ${ }^{\mathbf{0}}$ 1548, de 29 de março de 2012. Disponível em: < http://www.agencia.baciaspcj.org.br/docs/resolucoes/resolucao-semad-igam-1548.pdf>.

Acesso em: 20 fevereiro de 2014.

SILVA, D. D. da; MARQUES, F. de A.; LEMOS, A. F. Avaliação de metodologias de regionalização de vazões mínimas de referência para bacia do rio São Francisco. Engenharia na Agricultura, Viçosa, v. 17, n. $\quad 5, \quad$ p. $392-403.2009$. https://doi.org/10.13083/1414-3984.v17n05a07

SILVA, B. M. B. da. Influência da sazonalidade da disponibilidade hídrica nos critérios de outorga de uso da água e avaliação de índices para a gestão e planejamento de recursos hídricos na bacia do rio Paraopeba. 2012. Dissertação (Mestrado) - Universidade Federal de Viçosa, Viçosa, MG, 2012.

SOLERA, A.; PAREDES-ARQUIOLA, J.; ANDREU, J. AQUATOOLDMA: Entorno de desarrollo de sistemas de ayuda a la decisión en materia de planificación de la gestión de cuencas hidrográficas incluyendo utilización conjunta y criterios de calidad de aguas.

Manual de usuario. Valência: UPV, 2007. Disponível em: < https://aquatool.webs.upv.es/aqt/en/home/>. Acesso em: 14 jan. 2015.

SOUSA, H. T. de. Sistema computacional para regionalização de vazões. 2009. Dissertação (Mestrado) - Universidade Federal de Viçosa, Viçosa, 2009.

SUPRAM. Superintendência Regional de Regularização Ambiental - Triângulo Mineiro e Alto Paranaíba. Disponível em: <http://www.meioambiente.mg.gov.br/suprams-regionais > Acesso em: 14 ago. 2014.

UBERABA. Prefeitura Municipal. Secretaria de Desenvolvimento Econômico e Turismo. Uberaba em dados. Uberaba, 2008. Disponível em: < https://pt.slideshare.net/prefeituradeuberaba/uberaba-em-dados-17>. Acesso em: 15 de setembro de 2015. 